\title{
What Does Comparative Philosophy Mean to the Social Existence of a Female Chinese Scholar?
}

\author{
Eva KIT WAH MAN \\ Hong Kong Baptist University, Hong Kong SAR, China (evaman@hkbu.edu.hk)
}

In this short autobiographical essay, I reflect upon what comparative philosophy could mean to the social existence of a female Chinese scholar like me. I argue that comparative studies have been beneficial to people like me who live in bybrid, ex-colonial spaces. Comparative philosophy has allowed me to develop, and hone, my own understanding of issues pertaining to feminist theory and aesthetics. It has also aided me in recontextualizing and reappropriating some elements of my Confucian background.

Keywords: comparative aesthetics; comparative philosophy; Confucianism; cross-cultural studies; feminist theory; social existence

Philosophy has never been a popular major for female freshmen entering undergraduate studies in Hong Kong. Traditional parents thought that the ideal professions for their daughters were in teaching, nursing, social work, public relations, administration or support. The majors offered by the Faculty of Arts or Social Sciences provide skills that female students should acquire.

I joined the Faculty of Arts at the Chinese University of Hong Kong (CUHK) in the 1980s as a result of a heartbreaking incident. I was so devoted to acting and directing during my post-secondary school years that I came to learn about the first School of Communication at the Hong Kong Baptist College (HKBC). Yet bowing to the expectation of my father, I also applied to the Faculty of Arts at the CUHK. I was accepted by both institutions. I still recall receiving the call for an orientation camp from a CUHK student union member on a morning in July. My father picked up the phone. His face glowed with happiness and I dared not to tell him I was actually waiting for news from the HKBC. The admission letter from HKBC's School of Communication was dropped in our mailbox the next day. My father opened it. Chinese parents occasionally intrude on their children's privacy, as they think it is a necessary parenting practice. He tore the letter into pieces and labelled my dream "vanity." The School of Communication, according to him, was an incubating center for movie stars and television artists, which were professions full of temptation for riches and fame. I picked up the pieces of paper and soaked my pillows in tears that night, for my dream of being a performing artist was shattered.

I was offered an undergraduate placement by the Philosophy and Religious Studies Department at the CUHK. The first two weeks were tumultuous. I took Introduction to Religious Studies and Introduction to Philosophy to begin with. The reading assignments were more than a naïve young Christian girl like me could handle. They were abstract, sophisticated and unfamiliar. I was in the university library searching for encyclopedia and dictionaries, trying to understand every strange English word that I had not encountered before. I had no help at all, and I was desperate. These feelings changed when I met a tutor who demonstrated his strong passion for the philosophical reflections of Søren Kierkegaard. I then realized how influential a philosophy tutor could be.

The young senior, Stephen, took us all to a campsite. We formed a circle and listened to a Catholic person talking about his life story. His father was imprisoned for smuggling drugs when he was born and he had never met him. He was then adopted and found his sanctuary in the Catholic church. Kierkegaard's work

Journal of World Philosophies 2 (Summer 2017): 144-148 
on Christianity led him to deeper philosophical reflection. I have to say I was deeply moved by Stephen's delivery and lines of thought, and admitted immediately that this was what a university student should study, making enquiries about ultimate truths and values. I was proud to be a university student in Hong Kong, as there were only two universities in the ex-colony in the 1980s. It was so competitive that enrollment would make all parents proud, including my father.

My father, due to the Sino-Japanese war in the 1940s, never received any education beyond junior high school. Like most traditional Chinese fathers, he did not motivate his daughters to pursue higher education. However, under the umbrella of the Faculty of Arts, I was safe to choose a major. Yet, with all the practical and daily preoccupations that surround a woman, I shared Simone de Beauvoir's view that it is difficult for a woman to conceive metaphysics and all its fervors, when she has to respond to and be responsible for all of the concrete daily chores. My thought was boxed with romantic anticipations and love affairs in my youth from reading the Mills and Boons series. Yet, I was also inspired by the readings and discussions I was assigned as a philosophy undergraduate. Compared to my male classmates, I was driven by examinations, whereas they exercised their capabilities and keen interests in abstract thinking and logical analysis. I remembered I excelled in ethics and aesthetics courses, but hated courses such as symbolic logic and analytical philosophy.

I graduated with fair grades and honors, and remained a student and a graduate that not many teachers or classmates would mention or even remember. The only shining event in my undergraduate days was when I was named "Best Director" for a play I directed for an inter-college competition. After graduation, I entered the workforce as a civil servant, drank with teacups marked with the crown of Queen Elizabeth II and followed a nine-to-five workday routine. I was not happy and was never satisfied. I took classes in film criticism and rock music history after work just to continue the intellectual pursuit that was initiated by my major in philosophy. It only came to my belated awareness that philosophical orientation was successfully instilled in me, in a female embodied self and a person with an intellectual appetite. It is a feeling of a whole person, but not parts, that the so-called camps of ideas and substances, mind and body, and abstract and concreteness were all mingled in an integrated whole in my real existence.

Two years later, I became the first female program officer employed by a powerful associate Director of Broadcasting and worked at RTHK, the Hong Kong government radio and television. I had the opportunity to interview celebrated authors, film directors, artists and scholars. It was when I conducted the interviews that the intellectual thirst cried from inside: "Who am I and what am I doing here?" The shameful feeling of my ignorance and shallow knowledge drove me to make an immediate improvement. I could no longer bear failing to dig out in fullness from interviewees who were just too brilliant for my questions. I finally resigned from Radio Television Hong Kong and joined the Graduate School at CUHK as a Master student in philosophy.

This motion at that time of my life put a lot of pressure on my marriage. I was married to a man from a Chiu Chow background, which is a Cantonese clan that is well known for its traditional gender values and expectations on women. My then husband was not comfortable with my plan to pursue a graduate degree. The intimidating feeling intensified when my daughter was born. An interesting incident that I recall was how I hid myself in the small kitchen when my newborn was sleeping, reading Phenomenology of Aesthetic Experience written by Mikel Dufrenne. I was so into it that I did not notice my mother-in-law's shocked face when she found me hiding in the dark reading an English book, leaving my newborn behind. In her mind, the last thing a mother should be doing is reading and thinking. My newborn was taken away from me during the first two years of my motherhood. I was judged as being "unfit" for the role. While accompanying my daughter to Sunday school, on numerous occasions other mothers would come to me to report her "attention-seeking behavior" and to make comments, such as "Why are you so ambitious?" and "Why do you have to go for a Ph.D.?”

Journal of World Philosophies 2 (Summer 2017): 144-148 
Getting a Ph.D. in Philosophy continues to be something more perplexing than getting a medical degree for a Chinese woman, even in the ex-colony of Hong Kong. The choice is neither practical nor necessary. It is just too abstract and weird. It explains why when I was asked about what I was doing when I started teaching, my answer was always just "teaching." "Are you teaching in a primary school?" "In a secondary school?" "What kind of subject are you teaching?" You don't want to know the answers. When I got my Ph.D., I learned that I was one of the few female Ph.D. in philosophy in Hong Kong.

My marriage finally ended as a result of disagreements, wrong expectations and prejudices, and before that, psychological sufferings, hurtful words and indifference. It was during that period that I started to turn to feminist philosophy, a discipline that I had never been exposed to during my 10 years of university philosophy education. All of my professors were Chinese (mainly Taiwanese) males who did not encourage female students to study philosophy, but did not mind granting them high grades when they performed well. The least one would expect to learn from them was the gender dimension. My inclination toward feminist philosophy was not due to any external influences, but my own reflection on what had gone wrong in my marriage. The first initiative was a conference paper on Confucianism, Chinese women and family, which I was invited to deliver at a Christianity and Confucianism conference.

The readings related to Confucian teachings for women and their patriarchal backgrounds awoke my mind. They were so revealing. I started to look at my marital life and my perspectives, knowing that the issues or problems involved did not come from individuals or members of my ex-partner's family, but a collective consciousness that had a long tradition of placing gender in a social hierarchy and with a certain division of labor. Confucian discourses at the social level have shaped Chinese life and stereotypes. The economic and political grounds are just too clear to miss. The related understanding, as if something I learned for the first time, was groundbreaking for me. Not only was I very much interested in Confucianism and its gender implications, which spoke to my life as a Chinese woman, I was also fascinated by the philosophical agenda behind it. It integrated religious beliefs, metaphysics, cosmological structure and their correspondence to political-social power. The more understanding I gained, the more forgiving I became. Philosophy to me has never been so down to earth.

My encounter with feminist aesthetics came shortly after, with the discourses fascinating me to the same extent. Its modality shares that of Confucian philosophy and more so with Daoist philosophy, in terms of subject-object relationship, nature and humanity. The first volumes of work that I read include Hilde Hein and Carolyn Korsmeyer's edited work, Aesthetics in Feminist Perspective, ${ }^{1}$ and Peg Brand and Carolyn Korsmeyer's edited volume, Feminism and Tradition in Aesthetics. ${ }^{2}$ Feminist aestheticians refer to modes of patriarchal awareness, which contains Western thoughts of subject and object segregation and the renunciation of manifold phenomena in favor of dualism and a closed system of the world. They yearn for alternatives and new languages in aesthetics. They call for sociological and cultural perspectives to be introduced to the study of art, emphasizing the importance of the concepts of history, class, sex and culture in the determination of what constitutes so-called "good" art and for whom it has been created in a given period. In short, the primary function of a new theory is to identify art by sorting its multiple relationships into its contexts. The agenda spoke to me so well, as my social existence was like art calling for similar approaches to reading.

Moreover, aesthetics should not flee from experience to theories, which is the key to understanding women's art and art in general. If women's art is "a different logic, a different way of asking questions, a different kind of strength and weakness, friendship and enmity," as Hilde Hein suggested, it needs reading of concrete personal and social experiences. I was also under the influence of Suzi Gablik's work, Re-enchantment of Art, which does not equate aesthetics to alienation from the social world, but embodies modes of relatedness. ${ }^{3}$ She advocates a partnership model in art, which should be communicative and "compassionately" responsive, echoing with the notion of femininity. I aspired to this feminist agenda,

Journal of World Philosophies 2 (Summer 2017): 144-148 
promoting the relations between art, nature and life in the form of subject-to-subject relationships. I believed that aesthetic ideas should focus on bodily expressions rather than on pure concepts or speculations and that art should be evaluated according to its potential to promote a more effective, moral and satisfying life.

My life after divorce also demanded "a different logic, a different way of asking questions, a different kind of strength and weakness." I saw the pros and cons of my Confucian influences. Confucian governance turns to control and power, and forms a dualism of yin and yang, male and female and the five social relationships, which are between the emperor and minister, father and son, brother and brother, husband and wife, as also friend and friend respectively. Yet, at the philosophical level, it supposes harmonious relationships between subjects and objects and between Nature and humans. In this sense, it shares the modality of feminist aesthetics. I reflected seriously on Confucian metaphysical and ontological implications, which refer to in-depth religious beliefs in our integrated relationships with Nature or Heaven. These references are not just logical, theoretical inferences or pure speculations, but traditional convictions in the interaction and exchanges between humans and Nature. These are suggested in the mind and body practices that Confucius explicates through his teachings of music, and Mencius' later discussion on mind and body coherence. Confucian theories of art also target a social therapeutic model that feminist aestheticians advocate. All of these ideas were pillars in my later work in comparative studies. The more I explore, the more I learn about gender differences, think beyond gender in the social sense and seek solutions at the original source or at the metaphysical level.

Let me revisit another experience I had after my Ph.D. While I was writing my dissertation in June 1989, the June 4 massacre, during which the students' protests against the government in Beijing was suppressed by tanks and guns, causing hundreds of deaths, brought an aftershock. I migrated to Canada as a lot of Hong Kongers did, with the fear of Hong Kong being returned to China in 1997. I landed in Victoria, B.C., Canada as a new immigrant with my 4-year-old daughter. The inferiority complex, which arose as a stranger to a country whose mother tongue was not English and the isolation of being a new immigrant, a single mother, a graduate student, an Asian and a female were reinforced in a community and environment that I had difficulties engaging with. I lived in various forms of dualism: between citizenship and people in exile, being well established and being disorientated and Chinese culture and Western thoughts, etc. The disintegration experience later stimulated my keen interest in comparative studies, to inform findings of possible dialogues between different cultures, orientations, thinking and living paradigms. The first link I was thrilled to discover was the common agenda between feminist and Chinese philosophy.

As a liberal postgraduate I fought against Confucian gender norms and the social pressure exerted on me in my ex-marriage, as I was keenly aware of all of the rights-oriented traditions introduced in my early education in an ex-British colony. As mentioned above, my ex-husband's Chiu Chow community emphasized stereotypical gender relationships and the priority of community. I paid by living in anger and despair, facing all of the accusations that I received during my marriage. I gained a much better understanding and made reflective findings in feminist discourses and their conversations with Confucianism. I also contrasted their implications from the philosophical level to the social and political levels, which could be so different and contradictory.

Comparative studies are beneficial to people like me who live in hybrid, ex-colonial spaces. If comparative philosophy has been therapeutic for me, it is this statement that is telling: "Sometimes we can understand others just well enough to know that we don't understand them." ${ }^{4}$ Conducting comparative philosophy can be very difficult, not only because of the vast range of texts and their intellectual and historical contexts, but also because we tend to oversimplify and excessively contrast. Yet, the challenge is that discipline forces reflection on the most deeply entrenched and unquestioned assumptions of one's own traditions (ibid.). I have been so engaged in the critical practice that I have not asked myself why I still conduct research in comparative philosophy. Yet, this suggestion is telling-comparative philosophy is a

Journal of World Philosophies 2 (Summer 2017): 144-148 
sensible strategy for doing philosophy and that when facing hardships, it is simply a good strategy to consider a wide range of enduring and respected ideas (ibid.). Even more so, "It is that comparative philosophy can stretch one's sense of possibility, in this case, of human possibility. That is a benefit in itself" (ibid.). I have become more understanding and forgiving, to myself and to other people in my life.

Professor Eva Kit Wah Man is presently the Acting Director of the Film Academy and a full professor of the Humanities and Creative Writing Department of Hong Kong Baptist University. Her academic research areas include: Comparative Aesthetics, Neo-Confucian Philosophy, Feminist Aesthetics and Philosophy, Gender Studies and Cultural Studies. She has published numerous academic books, refereed journal articles, and creative prose writings in philosophy and aesthetics. Her recent book, Bodies in China: Philosophy, Aesthetics, Gender and Politics (2016) is jointly published by SUNY and Chinese University Press of Hong Kong. She is a trustee of the American Society for Aesthetics and a delegate-at-large of International Association of Aesthetics.

ed. Hilde Hein and Carolyn Korsmeyer, Aesthetics in Feminist Perspective (Bloomington and Indianapolis: Indiana University Press, 1993).

2 ed. Peg Brand and Carolyn Korsmeyer, Feminism and Tradition in Aesthetics (Pennsylvania: Pennsylvania State University Press, 1995).

$3 \quad$ Suzi Gablik, The Reenchantment of Art (N.Y.: Thames and Hudson, 1991).

$4 \quad$ David Wong, "Comparative Philosophy: Chinese and Western," The Stanford Encyclopedia of Philosophy, Spring 2017 Edition, ed. Edward N. Zalta (forthcoming URL

<https://plato.stanford.edu/archives/spr2017/entries/comparphil-chiwes/> Retrieved on Feb. 24, 2017). 